\title{
PRELIMINARY RESULTS OF SEA ICE FREEBOARD MEASUREMENTS OF BEAUFORT SEA FROM CRYOSAT-2 ALTIMETRY
}

\author{
Zhang Shengkai ${ }^{1}$, Zuo Yaowen ${ }^{1}$, Xiao Feng ${ }^{1, *}$, Yuan Lexian, Geng Tong ${ }^{1}$, Xuan Yue ${ }^{1}$ \\ ${ }^{1}$ Chinese Antarctic Center of Surveying and Mapping, Wuhan University, 430079 Wuhan, China - (zskai, lsyteamo, shaw89, \\ yuanlexian, t.geng, xuanyue)@whu.edu.cn
}

KEY WORDS: Arctic, Sea Ice, Beaufort Sea, Freeboard, CryoSat-2

\begin{abstract}
:
Satellite altimetry has been used to observe the Arctic sea ice in long term and large scale, and the records show a continued decline for Arctic sea ice thickness over decades. In this study, the sea ice freeboard in Beaufort Sea of Arctic have been estimated using CryoSat-2 data, and validated with Upward Looking Sonar (ULS) data of Beaufort Gyre Exploration Project (BGEP). The results show an obvious seasonal variation of the Beaufort Sea with a high reliability estimation of the sea ice freeboard. The average height of the sea ice freeboard increase from January to March and achieve the maximum value $0.38 \mathrm{~m}$ in March. The sea ice melts after March and the average height of the sea ice freeboard reduces to the minimum $0.12 \mathrm{~m}$ in August. In the next few months the sea water begins to freeze and the average height of the sea ice freeboard will increase to the maximum value.
\end{abstract}

\section{INTRODUCTION}

Sea ice plays a very important role in Earth's radiation balance because of the high reflectivity of sea ice. The reflectivity is decided by spatial distribution and extent of the sea ice (Lee et al., 2016). In addition, energy budget of the sea ice growth and ablation drives the global ocean water circulation and thermohaline circulation. Arctic sea ice is a significant component of the global climate system. The minimum Arctic sea ice in summer has been subject to an average reduction of more than 10\% per decade since 1979 (Stroeve, et al., 2012). Ice, ocean, and atmosphere, is the three components of Arctic climate. The heart of this system is one of the least studied bodies of water on the planet: the Beaufort Gyre, a slowly swirling bowl of icy water. Beaufort Sea lies north of Alaska and northwest of Canada coast and also west of Arctic Arch and east of Chukchi Sea, most of Beaufort Sea is more than $100 \mathrm{~m}$ deep and is part of the Canada Basin (Andrew et al., 2013). Recent studies suggest that the natural rhythms of the Beaufort Gyre have been tipped out of balance because of global warming. Thus, it's very important to figure out the sea ice change in Beaufort Sea and its impacts on Beaufort Gyre and Arctic sea ice change.

Sea ice thickness is difficult to measure due to the complex environmental factors and physical processes of the sea ice. There are three different methods to measure sea ice thickness including direct field measurements (drilling hole, underwater sonar, ship-measured, electromagnetic induction), microwave remote sensing and satellite altimetry. Direct field measurements provide accurate sea ice thickness information which can be used for calibration and validation. Microwave remote sensing and satellite altimetry methods are used to estimating sea ice thickness at large scale with lower accuracy than direct field measurements (Zygmuntowska et al., 2014). Laxon et al. (2003) estimated Arctic sea ice thickness distribution using ERS-1 and ERS-2 data. Giles et al. (2008) retrieved Arctic sea ice thickness using ENVISAT data during 2002-2008. Kwok et al. $(2009,2014)$ used ICESat and CryoSat2 data to estimate Arctic sea ice thickness. Laxon et al. (2013) and Ricker et al. (2015) used data of the new generation radar altimetry satellite CryoSat-2 to retrieve the Arctic sea ice distribution.

In this paper, CryoSat-2 data are used to estimate the sea ice freeboard of Beaufort Sea, Arctic. Upward Looking Sonar data of Beaufort Gyre Exploration Project (BGEP) have been used to validate the sea ice freeboard results.

\section{DATA}

\subsection{CryoSat-2 Data}

CryoSat-2 is developed by the European Space Agency (ESA), launched in 08 April 2010 (Wingham et al., 2006). The altitude of CryoSat-2 is $730 \mathrm{~km}$ with inclination of 92 degrees, and the repeat cycle is 369 days (5344 orbits) with 30-day sub-cycle. CryoSat-2 carries the Synthetic Aperture Interferometric Radar Altimeter (SIRAL) as the main payload of the satellite which has extended capabilities to meet the measurement requirements for ice sheet and sea ice. The SIRAL samples the surface every $300 \mathrm{~m}$ along-track using three different measurement modes, LRM, SAR and SARIn. The low-resolution mode (LRM) is similar to the operation of conventional pulsewidth-limited altimeters and is used over ice sheet interiors, where the slopes of the surface are small. It is also used over ocean. In the synthetic aperture (SAR) and synthetic aperture interferometric (SARIn) modes, SIRAL samples the surface with a higher pulse repetition frequency than in LRM. SARIn measures the steep areas at the margins of the ice sheets and ice caps, whereas the SAR mode is used to detect sea ice.

In this paper the CryoSat-2 L2 data were used to estimate the sea ice freeboard which is fully corrected for ionospheric delay, propagation delays, measurement geometry, and other geophysical effects such as atmospheric and tidal effects.

\subsection{Validation Data}

Upward-Looking Sonar (ULS) data of Beaufort Gyre Exploration Project is used to validate the accuracy of freeboard

\footnotetext{
* Corresponding author
} 
inversion. The major objective of the observational program is to determine freshwater content and freshwater fluxes in the Beaufort Gyre during a complete seasonal cycle (Proshutinsky et al., 2009). In August 2003, scientists of BGEP began to acquire time series measurements of temperature, salinity, currents, geochemical tracers, sea ice draft, and sea level using moorings, drifting buoys, shipboard, and remote sensing measurements. The moorings precisely measure the variations of the vertical distribution of freshwater content and sea ice draft at representative locations. Data is measured in four locations and the distributions of measured points are presented in Figure 1. Only A, B, and D have sea ice draft data in 2013.

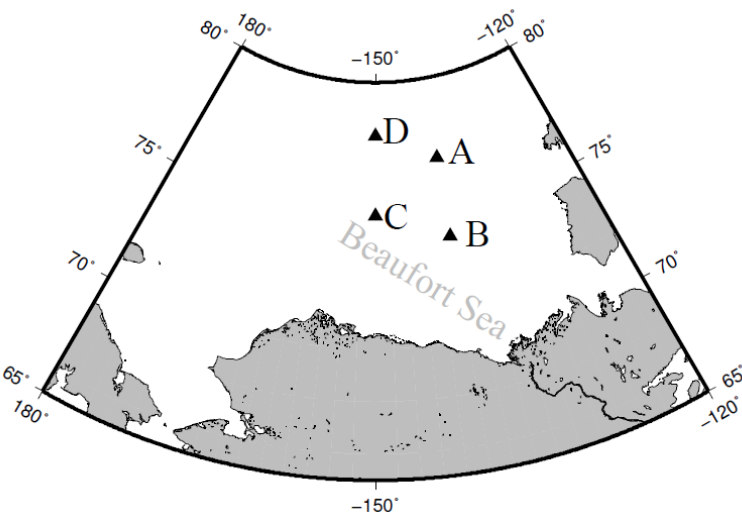

Figure 1. Locations of the four ULSs of the Beaufort Gyre Exploration Project

\section{METHODS}

\subsection{Surplus Altitude Extraction}

The surplus altitude in this paper refers to the difference between the surface height and the corresponding mean sea surface height. The surface height and mean sea surface height can be acquired from CryoSat-2 L2 product. The surplus altitude is fully corrected for instrument effects, measurement geometry, propagation delays and other geophysical effects.

Figure 2 shows the data of orbit 79, where lateral axis represents the distance along the orbit with the unit of kilometer, vertical axis represents the height with the unit of meter. The curve made by black points stands for the mean sea surface height, blue points represent the surface height, and red points represent the surplus altitude.

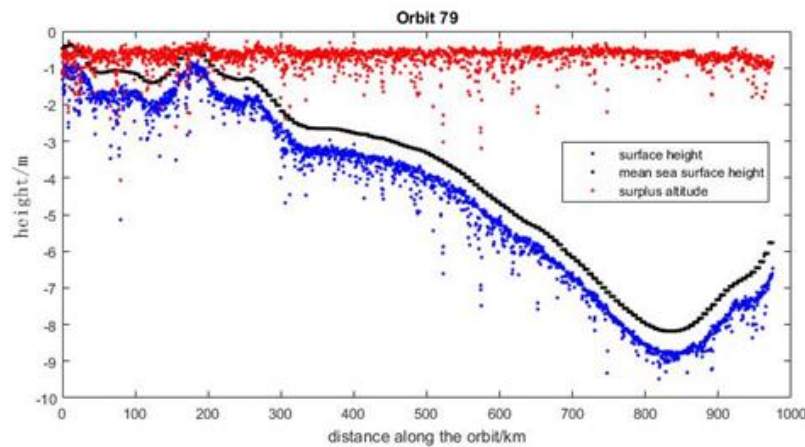

Figure 2. Surplus altitude extraction results of orbit 79

It can be concluded from Figure 2 that the elimination of mean sea surface height has a contribution to remove the effects of the geoid and the mean dynamic topography, also make sure in subsequent steps the value we choose represents for the relative sea surface instead of the geoid or the lower points of sea surface dynamic topography. After that the surplus altitude can be used to estimate the relative sea level.

\subsection{Outliers Elimination}

As shown in Figure 2, the surplus altitude of most points is concentrated distributed. However, there are outliers which undoubtedly have a significant impact on the extraction of relative sea level.

First, we choose $-2 \mathrm{~m}$ as the threshold and eliminate the values less than $-2 \mathrm{~m}$. There are still some outliers after elimination. Then different standard deviations are chosen to filter the data every $50 \mathrm{~km}$ along the orbit to ensure the integrity of valid data and the elimination of exceptional values. Figure 3 shows the screening effect of different standard deviation and Table 1 shows the rejection rate of orbit 79 .
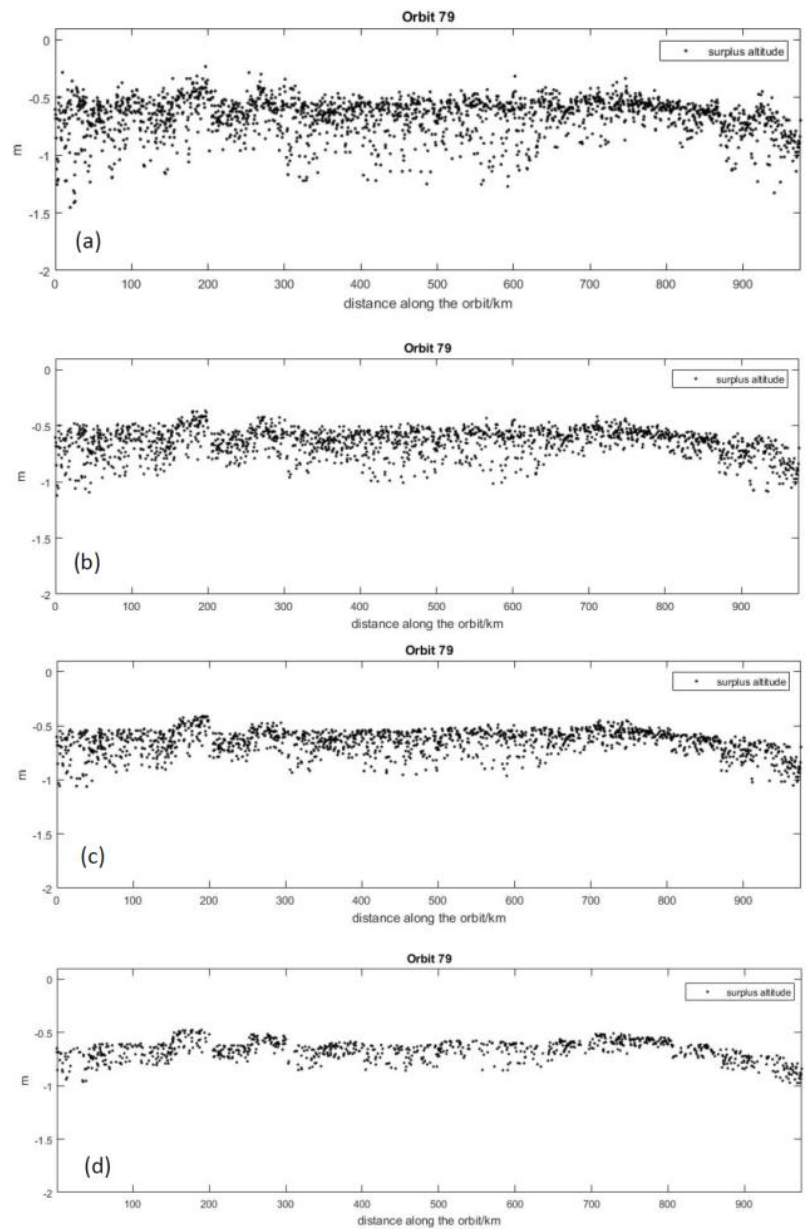

Figure 3. Outliers elimination results of different standard deviation. (a) eliminated by 2 times standard deviation, (b) eliminated by 1 times standard deviation, (c) eliminated by 0.8 times standard deviation, (d) eliminated by 0.5 times standard deviation.

\begin{tabular}{|c|c|c|c|}
\hline Orbit 79 & $\begin{array}{c}\text { Data } \\
\text { volume }\end{array}$ & $\begin{array}{c}\text { Data volume } \\
\text { after elimination }\end{array}$ & $\begin{array}{l}\text { Rejection } \\
\text { rate }\end{array}$ \\
\hline $\begin{array}{c}2 \text { times standard } \\
\text { deviation }\end{array}$ & 2107 & 1996 & $5.3 \%$ \\
\hline $\begin{array}{c}1 \text { times standard } \\
\text { deviation }\end{array}$ & 2107 & 1733 & $17.8 \%$ \\
\hline $\begin{array}{c}0.8 \text { times standard } \\
\text { deviation }\end{array}$ & 2107 & 1526 & $27.6 \%$ \\
\hline 0.5 times standard & 2107 & 945 & $55.1 \%$ \\
\hline
\end{tabular}


deviation

Table 1. Rejection rate of different standard deviation

If 2 times standard deviation is chosen for the elimination, the rejection rate is too small and the exceptional values may still remain as shown in Table 1 and Figure 3. In that case, the inversion of freeboard will be higher than the real value. If we choose 0.5 or 0.8 times standard deviation, a lot data would be eliminated including some useful data and the thickness of freeboard can't be reflected effectively. From Figure 3(b) we can see that the distribution of surplus altitude is in a sensible level and the integrity of data is guaranteed. Based on the actual situation and the test, we use 1 times standard deviation to do the elimination.

\subsection{Leads Identify}

The key problem to determine freeboard from CryoSat-2 elevations is to estimate the local sea level by identifying leads. The minimums elevations along the CryoSat- 2 profiles are indicative of areas of open leads. We take the average of three minimum values in $20 \mathrm{~km}$ as the local sea level to estimate Arctic sea ice freeboard.

\section{RESULTS}

\subsection{Freeboard Distribution in Beaufort Sea}

Finally, we derived the sea ice freeboard of Beaufort Sea. Figure 4 shows the sea ice freeboard distribution in 2013. The unit of freeboard is meter.
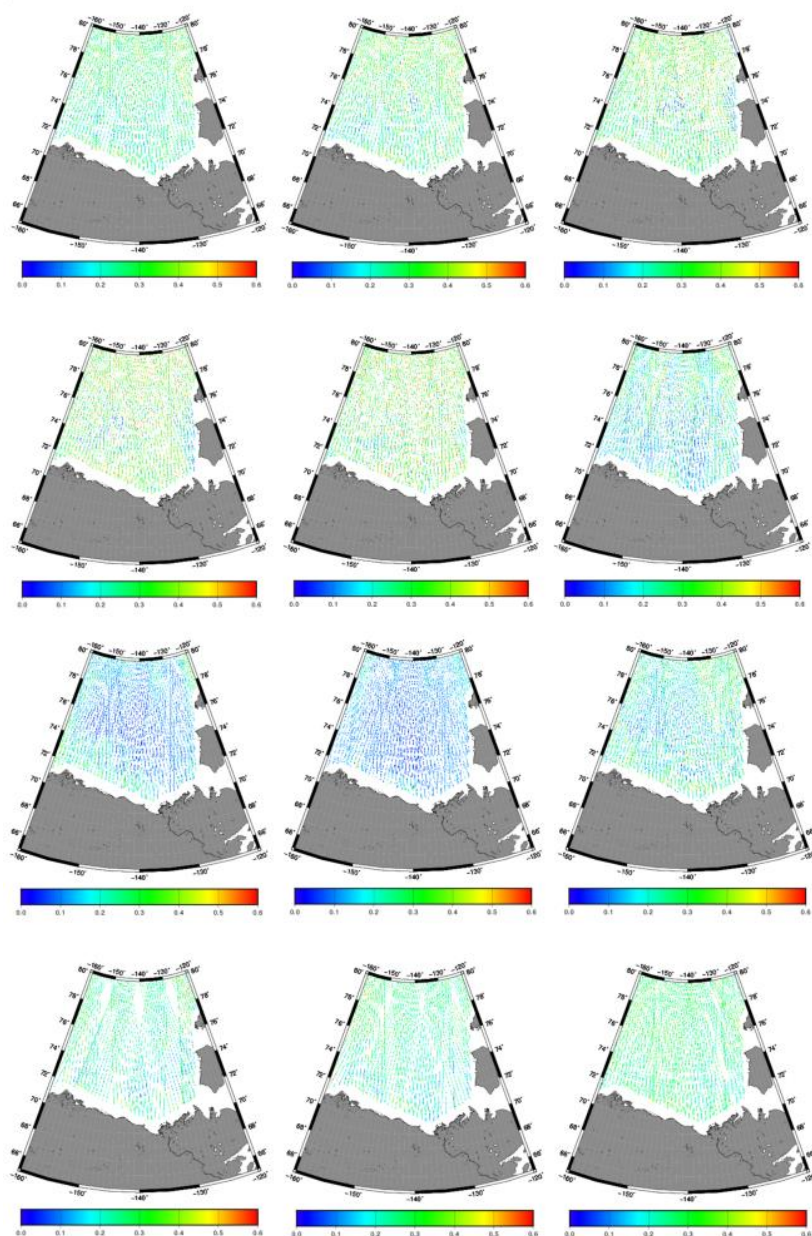

Figure 4. Sea ice freeboard distributions of Beaufort Sea from January to December in 2013 (from left to right, top to bottom)
The sea ice extent and thickness reach the maximum in March during this year. The freeboard distribution from January to March is shown in the first row of Figure 4, sea ice covers the whole Beaufort Sea and the height of freeboard is growing. The distribution of freeboard changes with the latitude range from $0.2-0.5 \mathrm{~m}$ and in high latitude regions the freeboard is larger. The freeboard near the coast is relatively low and in January the freeboard near coast is around $0.2 \mathrm{~m}$ and in some regions the freeboard is only $0.1 \mathrm{~m}$. In March the average freeboard grows to $0.38 \mathrm{~m}$ and then the sea ice begins to melt from April and the freeboard start to decrease. The freeboard have an obvious decreasing trend from April to June shown in second row of Figure 4, the decrease of freeboard from $72^{\circ} \mathrm{N}$ to $76^{\circ} \mathrm{N}$ is more significant. The freeboard in lower latitude regions reduces to near $0.15 \mathrm{~m}$ and in high latitude regions near $80^{\circ} \mathrm{N}$ the freeboard is around $0.3 \mathrm{~m}$ in the June.

From July to September is the summer of Arctic and during this period the freeboard continue to decrease and reach the minimum in August. In August, the average freeboard is only $0.12 \mathrm{~m}$. Then from September the water start to freeze and the freeboard start to increase. The freeboard in September has an obvious increase than August and after that the freeboard continue to increase in next few months as shown in the third row of Figure 4. In December the average freeboard is $0.26 \mathrm{~m}$, close to the freeboard in January and the same with the freeboard distribution.

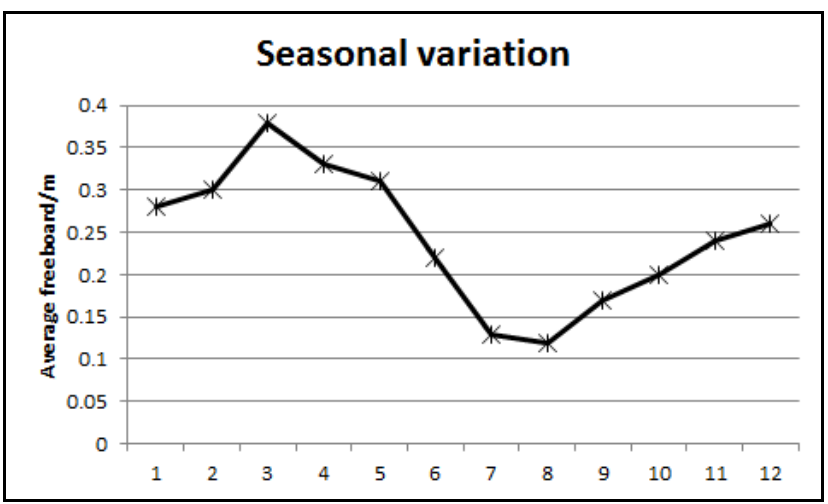

Figure 5. Seasonal variation of average freeboard in Beaufort Sea

Figure 5 shows the seasonal variation of average freeboard in Beaufort Sea. The freeboard in Beaufort Sea has clearly seasonal variation based on our results. The average freeboard increase from January to March and reach the maximum $0.38 \mathrm{~m}$ in March. Then from March to August the average freeboard continues to decrease and reach the minimum $0.12 \mathrm{~m}$ in August. After that the water begins to melt and freeboard grows, the average freeboard became very close to that in January.

\subsection{Validation}

Upward looking sonar data of BGEP was used to examine the accuracy of the sea ice freeboard results calculated in this paper. The sea ice draft data from ULS was compared with the nearest CryoSat-2 observations. Figure 6 shows the comparison between ULS data from BGEP and the results from CryoSat-2 in this study. The sea ice thickness variation trends from ULS and CryoSat-2 are consistent. Table 2 is the statistics of differences between ULS and CryoSat-2.

In Table 2, the differences between sea ice draft from BGEP and the results in this study are less than $0.2 \mathrm{~m}$, in point $\mathrm{A}$ the 
difference is only $-0.08 \mathrm{~m}$. Results show that the inversion and the measured results are highly unified.

\begin{tabular}{cccc}
\hline Locations & $\begin{array}{c}\text { Draft from } \\
\text { ULS/m }\end{array}$ & $\begin{array}{c}\text { Draft in this } \\
\text { study/m }\end{array}$ & Differcen/m \\
\hline $\mathrm{A}$ & 1.29 & 1.37 & -0.08 \\
\hline $\mathrm{B}$ & 1.23 & 1.05 & 0.18 \\
\hline $\mathrm{D}$ & 1.47 & 1.63 & 0.16 \\
\hline
\end{tabular}

Table 2. Statistics of differences between ULS and CryoSat-2
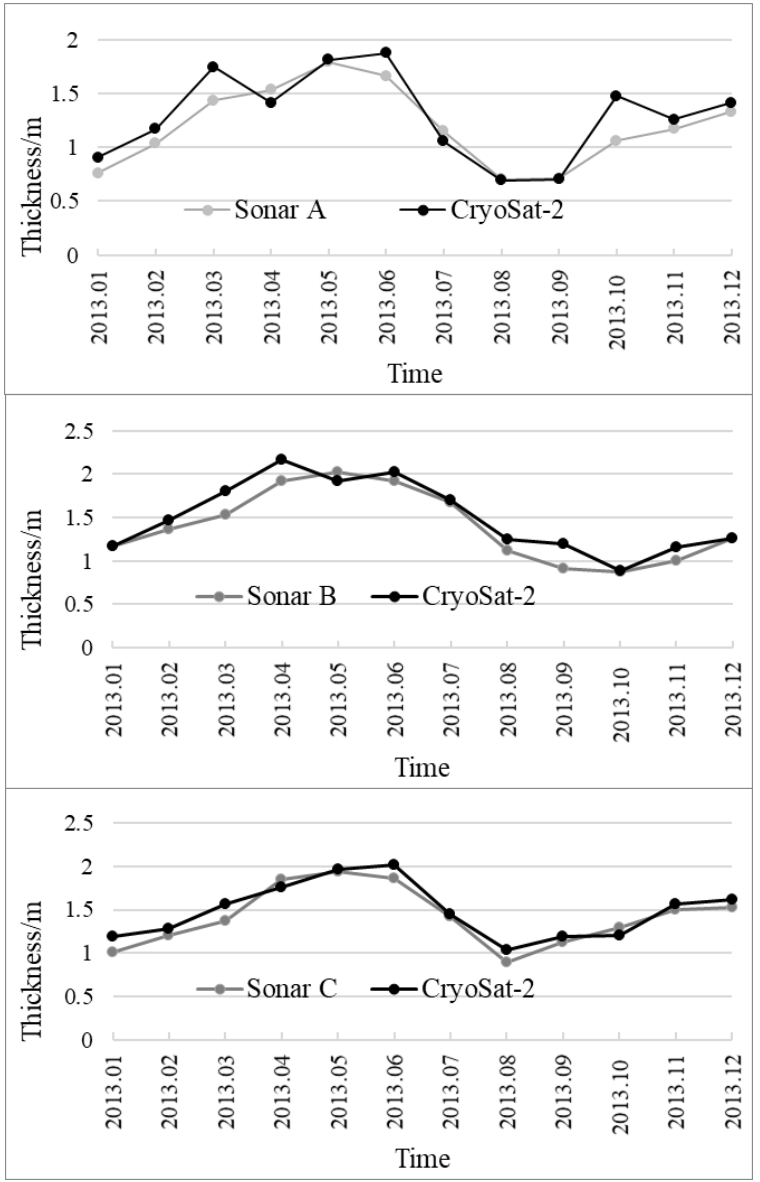

Figure 6. Comparison of ULS data from BGEP and the results in this study

\section{CONCLUSIONS}

In this paper the sea ice freeboard in Beaufort Sea in 2013 have been estimated. Compared the results with the ULS data from BGEP we can conclude that the freeboard estimated from CryoSat-2 altimeter data have a high reliability. Based on the freeboard distribution in each month we can conclude that the sea ice thickness change with the latitude, the freeboard is larger in high latitude regions than that in low latitude regions. The average freeboard has obvious seasonal variation characteristics, from January to average freeboard stay in a growing state and reach the maximum $0.38 \mathrm{~m}$ in March. Then the sea ice start to melt from April to August, from May to July the average freeboard has been falling fast and reaches the minimum $0.12 \mathrm{~m}$ in August. The water begins to freeze in September and the average freeboard has returned to growth slowly and steadily, in December the average freeboard and the freeboard distribution are very close to that in January.
Since the CryoSat-2 starts work from August 2010, analyses of seasonal and annual variation of sea ice with data for several years are available and valuable in the following study.

\section{ACKNOWLEDGEMENTS}

This work was supported by the National Key Research and Development Program of China (no. 2017YFA0603104), the National Natural Science Foundation of China (no. 41531069, 41730102, 41706216), the Independent Scientific Research Program for Cross-disciplinary of Wuhan University (no. 2042017kf0209, 2042018kf0032) and China Postdoctoral Science Foundation (no. 2017M612507).

\section{REFERENCES}

Andrew, R., Mahoney, H., Allison, G., et al. 2013. Landfast sea ice extent in the Chukchi and Beaufort Seas: The annual cycle and decadal variability. Cold Regions Science and Technology, 103:41-56.

Armitage, T., Ridout, A. 2015. Arctic sea ice freeboard from AltiKa and comparison with CryoSat-2 and Operation IceBridge. Geophysical Research Letters, 42: 6724-6731.

Giles, K., Laxon, S., Ridout, A. 2008. Circumpolar thinning of Arctic sea ice following the 2007 record ice extent minimum. Geophysical Research Letters, 2008, 35(L22): 113-130.

Kurtz, N., Galin, N., Studinger, M. 2014. An improved CryoSat-2 sea ice freeboard and thickness retrieval algorithm through the use of waveform fitting. The Cryosphere, 8(1): 721768.

Kwok, R., Cunningham, G., Wensnahan, M., et al. 2009. Thinning and volume loss of the Arctic Ocean sea ice cover, 2003-2008. Journal of Geophysical Research, 114(C7): 371377.

Kwok, R. 2014. Simulated effects of a snow layer on retrieval of CryoSat-2 sea ice freeboard. Geophysical Research Letters, 41(14): 5014-5020.

Laxon, S., Peacock, N., Smith, D. 2003. High interannual variability of sea ice in the Arctic region. Nature, 425(6961): 947-950.

Laxon, S., Giles, K., Ridout, A., et al. 2013. CryoSat-2 estimates of Arctic sea ice thickness and volume. Geophysical Research Letters, 40(4): 732-737.

Lee, S., Im, J., Kim, J., et al. 2016. Arctic Sea Ice Thickness Estimation from CryoSat-2 Satellite Data Using Machine Learning-Based Lead Detection. Remote Sensing, 8, 698.

Proshutinsky, A., Krishfield, R., Timmermans, M., et al. 2009. Beaufort Gyre freshwater reservoir: State and variability from observations. Journal of Geophysical Research: Oceans, 114(C1): C00A10.

Ricker, R., Hendricks, S., Perovich, D., et al. 2015. Impact of snow accumulation on CryoSat-2 range retrievals over Arctic sea ice: An observational approach with buoy data. Geophysical Research Letters, 42(11):4447-4455. 
Stroeve, J., Serreze,M., Holland, M., et al. 2012. The Arctic's rapidly shrinking sea ice cover: a research synthesis. Climatic Change, 110 (3):1005 - 1027.

Wingham, D., Francis, C., Baker, S., et al. 2006. CryoSat: A mission to determine the fluctuations in earth's land and marine ice fields. Adv. Space Res. 37, 841-871.

Zwally, H., Yi, D., Kwok, R., et al. 2008. ICESat measurements of sea ice freeboard and estimatesof sea ice thickness in the Weddell Sea. Journal of Geophysical Research, 113(C2): C02515.

Zygmuntowska, M., Rampal, P., Ivanova, N., et al. 2014. Uncertainties in Arctic sea ice thickness and volume: new estimates and implications for trends. The Cryosphere, 8(2): $705-720$.

Revised April 2019 